\title{
Food additives. Use, intake and safety
}

\author{
By Nils-Gunnar Ilbäck and Leif Busk
}

\begin{abstract}
Today we have about 300 approved food additives on the European market and all of them have been evaluated for safety by the European Commission's expert advisory body - the Scientific Committee for Food (SCF). There are fundamental requirements for approval of a food additive. The additive has to be of value for the consumer or necessary for the handling and distribution of the food. In addition, it has to be toxicologically acceptable according to European Community regulatory requirements. For most additives, a numerical $(\mathrm{mg} / \mathrm{kg}$ bw/day) ADI-value (Acceptable Daily Intake) has been determined that shows how much it is possible to consume each day during a life time without any appreciable risk of adverse effects. If no adverse effects have been demonstrated in the safety evaluation no numerical value for the ADI is specified and the additive may be used according to the principles of Good Manufacturing Practice (quantum satis), i.e. the minimum amount necessary to produce the desired effects. When the intake of certain food additives can be assumed to be high in relation to the ADI, this should always trigger additional consideration and action. For such food additives it is important that continuous monitoring of use and intake is performed, that potentially sensitive groups and/or individuals are identified and that intake calculations are performed to ensure that the ADI is not exceeded.

Key words: Consumption, food additives, intake, regulatory requirements, safety assessment
\end{abstract}

\section{Introduction}

The major goal for the National Food Administration (NFA) is to ensure the safety of food. In order to achieve this, it is important to perform risk assessments of microorganisms and chemicals (contaminants and food additives) in food. The major reason for using food additives is to preserve and in different ways improve the quality of food. Food additives must be of value for the consumer or necessary for the handling and distribution of the food and they have to be toxicologically acceptable. In order to keep the intake of food additives within safe levels it is important to regulate the use of the additives in food, as well as to estimate consumption of the foods that contain the specific additive.

Nils-Gunnar Ilbäck PhD. Toxicologist at National Food Administration, Uppsala, and Assoc. Prof. at Section of Infectious Diseases, Department of Medical Sciences, Uppsala University Hospital, Uppsala, Sweden. Leif Busk PhD. Head of R\&D, Research and Development Department, National Food Administration, Uppsala, Sweden.

Correspondence: Nils-Gunnar Ilbäck, Toxicology Division, National Food Administration, P.O. Box 622, SE-751 26 Uppsala, Sweden.

E-mail: ngil@slv.se
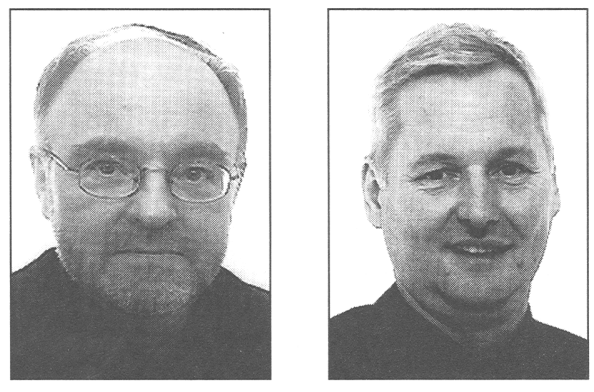

The use of food additives originated in ancient times. Far back in time people understood that some foods contained natural chemical compounds that could be used in food storage, although the structure and mechanisms of action of the substances were unknown. For example, the naturally occurring chemical substance benzoic acid (E210) is present in several berries and fruits, such as lingon berries, and acts as a preservative and protects against yeast, bacteria and fungi. Thus, lingon berries have historically been used to preserve fruit that could not be stored in other ways.

In previous times it was not possible to get pure chemicals, but today we use either synthetically produced food additives or additives extracted and purified from natural sources with well-described mechanisms of action. Since 1920, the use of officially approved food additives has become common (1). However, in recent decades the regulation of food additives has become a matter of controversy. Although informed individuals generally acknowledge that the quality and safety of food have improved during the past 100 years, some individuals disagree and a few disagree vigorously. Explanations for this controversy, which is likely to continue, are easy to identify and will be discussed in the following text.

It is not permitted to use additives in food unless they are pure and have been evaluated for safety. The requirements for the safety evaluation of food additives are very similar to those for pharmaceutical compounds and this will be further dis- cussed in the section "Safety evaluation of a food additive". Furthermore, food additives cannot be used in our food unless they are of benefit for the consumer or needed for the handling of the food. Today we have about 300 approved food additives and about 2500 flavouring agents on the market. The use of food additives is strictly regulated, but at present this is not the case for the flavouring agents, which are presently being evaluated within the European Union (see section "Flavouring agents").

\section{Food additives}

There are two major categories of food additives, enrichment substances and the technological additives. Enrichment substances are used to improve the nutritional value of food and have been used as a tool in reducing deficiency diseases. For example, iodine is added to salt to avoid goitre and A/D-vitamins are added to margarine to avoid health effects due to deficiency of these nutrients. However, deficiency diseases are not a major problem in Europe today and the need for enrichment has thus become less. The major area today is technological food additives and the present review article will focus on the use and safety of these agents. Technological food additives are mainly used to increase the shelf life of food (preservatives and antioxidants), or to give it a better taste (sweeteners and flavouring agents), or to change its consistency (emulsifiers and thickeners).

Today we have about 300 technological food additives that are approved for use 
and they can be divided into sub groups (2). Most of the additives are present in nature as natural constituents, of for example, fruits and vegetables. However, some of them are now produced synthetically. Other additives that are produced synthetically are not present in nature. Semi-synthetic additives are natural compounds that have been chemically modified. Nevertheless, all these food additives, except for the flavouring agents, are pure compounds that have been evaluated for safety and their use and intake are regulated, as will be discussed in the present article. However, there are presently no regulatory rules for flavouring agents, but such rules will be introduced in the near future following an ongoing safety evaluation in the European Union (see section "Flavouring agents").

The main groups of food additives and their areas of use will be briefly described in the following section:

Colouring agents and dyes: It is not permitted to use colouring agents and dyes in our staple foods. The reason is partly the general restrictive attitude to additives and partly the fact that staple foods are consumed in high amounts.

Preservatives: These additives are used to preserve and protect the food from invasion and degradation induced by microorganisms such as bacteria, fungi and moulds. Preservation also gives protection from natural toxins that may be produced by microorganisms. In earlier days, people used air-drying, smoke, salt and fermentation as natural preservatives. Some of these methods are used even today, but now we also have other methods, such as heat treatment, deep-freezing and chemical preservation.

Antioxidants: These are used to protect fat from becoming rancid and fruit containing food from discolouration. Vitamins (such as $A, D, E$ and $B_{2}$ ) that are sensitive to degradation can also be protected by the action of antioxidants.

Emulsifiers-, stabilizing- and thickening agents, including anti-caking agents: This is an extensive group with several different compounds intended to be used in order to affect the consistency of foods. Some compounds in this group of additives have caused concern among consumers, for example the anti-caking agent sodiumferrocyanid (E 535) in salt (see section "Flavouring agents").

Sweeteners: There are two main groups of sweeteners, the natural and the synthetic (artificial) sweeteners. The natural sweeteners contain energy and can be further subdivided in one group of general sugars such as glucose, sucrose and fructose, and another group of sugar alcohols, such as sorbitol and xylitol (Table 1). The second group contains the synthetic sweeteners without energy, such as aspartame, acesulphame $\mathrm{K}$, saccharin and cyclamate. This group of artificial sweeteners has caused a lot of debate regarding safety, which will be discussed in a following section "Alarm in the media".

Additional additives, such as $\mathrm{pH}$ regulators: In this group there are different acids, bases and salts, for example glutamic acid and its salts (E620-625) that are used as taste intensifiers. These are also additives that over the years have caused headlines in the media and public debate (section "Alarm in the media").

Flavouring agents: This group of food additives is used to give the foods a special aroma or taste. Flavouring agents can be produced artificially or extracted from natural sources. Some of these artificially produced compounds are present in nature, whereas others are not. They can be used either individually or in mixtures of flavouring substances. This is a large group, approximately 2500 substances on the market, and so far their use has not been regulated as strictly as other food additives (see section below).

\section{Flavouring agents - a very special group of food additives}

The flavouring agents are a very special and complex group of additives: since they occur naturally, and are not regulated, they can not be regarded as "normal" food additives. Natural sources of flavourings are materials of vegetable or animal origin, some of which are consumed as food (3). For most of these flavouring substances and mixtures we need more information about their toxicity, the amount that is used as food additives and in which foodstuffs they are actually used.

Some of the naturally occurring flavouring agents may be toxic to humans in high doses and are of more concern than the other food additives that are well regulated. For example, hydrogen cyanide is a poison well-known to readers of crime novels, it can also be a hazardous pollutant in occupational exposure in industry, it can be present as a food additive in salt as sodium ferrocyanide (E 535) and it can also be a flavouring agent that is present naturally in bitter almonds and in stone fruits (4). When used as a food additive, sodium ferrocyanide (E 535) does not decompose or release cyanide. As other regulated food additives it has been evaluated for safety and is of no concern. On the other hand, when cyanide is ingested as a
Table 1: Sweeteners used in Sweden, an example of a group of food additives that are of interest for many consumers, not only diabetics. Sugars are not regarded as food additives.

\section{Energy containing sweeteners}

Sugars

Saccharose

Fructose

Glucose

Lactose

Maltose

Sugar alcohols

Sorbitol

Mannitol

Xylitol

Isomalt

E 967

Lactitole

E 953

Maltitol

E 966

E 965

Energy free sweeteners

Artificial sweeteners

Acesulfame K $\quad$ E 950

Aspartame

E 951

Cyclamate

E 952

Saccharin

E 954

Natural sweeteners

Taumatine

E 957

Neohesperidin DC E 959

bitter almond derived flavouring agent, the deadly dose is $6-10$ bitter almonds for a child and 40-60 almonds for an adult. Thus, it is very important to evaluate and regulate the use of all these naturally occurring and sometimes dangerous flavouring substances in the same way as for other food additives.

Within the EU there is an ongoing programme to evaluate 3000 flavouring agents within 5 years (by the end of 2005). The Council of Europe is presently evaluating 600 natural sources of flavourings: 101 of these evaluations have been finalised to date (3). The safety evaluation procedure used by EU, provides a scientifically based practical method of integrating data on intake, structure-activity relationships, metabolism and toxicity to evaluate flavouring substances in a timely manner. The procedure has been used recently by the Joint FAO/WHO Expert Committee on Food Additives (JECFA), as an advisory board, to evaluate a total of 263 flavouring substances (5). The problem with a safety evaluation of mixtures of flavouring agents could be illustrated by the coffee bean flavour that is used in instant coffee, chocolate, ice cream, sweets, soft drinks, etc. This flavour contains more than 900 chemically defined substances but only a limited and specifically selected number of them are used for the "coffee flavouring mixtures" in foods. However, the composition of the flavouring mixture is in most cases unknown, except to the industry. This illustrates how 
Figure 1. Toxicological data needed for safety assessment and ADI.

- Metabolism and Pharmacokinetics (ADME-studies)

- Sub-Acute / Sub-Chronic toxicity (28-90 days in the diet)

- Reproductive toxicity studies

- Teratology studies in 2 species

- Short-term and in vitro tests for Mutagenicity / Clastogenicity

- Chronic toxicity (long-term dietary, e.g. 2 year rat)

- Carcinogenicity, normally in 2 rodent species

- Mechanistic / Toxicological studies with structural analogs

Figure 2. The value of different types of studies in risk assessment. The value of different types of studies in risk assessment is increased the closer we get to humans.

\begin{tabular}{ll}
\hline Epidemiology & V \\
Animal experiments & A \\
Short term tests & U \\
- Sh
\end{tabular}

difficult this area is regarding monitoring, safety assessment and regulations.

\section{Food additives are specified on the food package}

All food additives that are used in a foodstuff should be declared on the label on the package to make it possible for the consumer to identify them. This is called the specification of the ingredient content. Each additive should be declared by its function, for example aspartame should be labelled as a sweetener, followed by the name aspartame or the specific identity number (E-number), that is E951 for aspartame. The E-number shows that the additive has been evaluated for safety and is permitted for use within the European Union (see section below). In some cases other information should also be given on the label. For example, aspartame is a source of phenylalanine and this must be stated on the label since some people have the disease phenylketonuria (PKU) that make them unable to metabolise this amino acid. Although flavouring agents are by definition additives, at present they do not have to be individually specified or declared. Thus, flavouring agents are declared as a group which means that the individual substances as well as the total number of added substances are unknown.

\section{Safety evaluation of a food additive}

Increasing global trading has increased the number of commercially available food products on the market. This increase is associated with the possibility that new and unapproved additives will appear on the market, and that "old additives" will be used in unacceptable amounts. With several hundred food additives on the market, it is important that each of them is subject to a thorough scientific evaluation and regulation $(6,7)$. There are fundamental demands for approval of a food additive. The food additive has to be of value for the consumer or necessary for the handling and distribution of the food, as well as being toxicologically acceptable, according to regulatory requirements within the European Community.

All approved food additives on the Swedish market have been evaluated for safety either by Joint FAO/WHO Expert Committee on Food Additives (JECFA) (8) or the Scientific Committe for Food (SCF), which both propose ADI-values (The Acceptable Daily Intake). In the USA, the Food and Drug Administration (FDA) does the corresponding work. The JECFA evaluations are continuously published as monographs, whereas the earlier work of SCF was not officially published in detail. However, SCF-reports (opinions) from recent years are available on the Internet. Thus, the most important work regarding evaluation of use, intake and safety of food additives in Sweden is today performed by the SCF and their Working Group for Food Additives. This Working Group consists of about 15 independent scientists, half of them are members of the SCF and the other half are ad hoc experts. The author (NGI) participates as ad hoc expert.

When a company/producer would like to put a new additive on the EU market, they have to submit an application to the SCF. In this expert group additives are evaluated for safety and individual ADIvalues are set before the additives are allowed to be used in the different food products (Figure 1). Furthermore, the maximum amount of the additive that is allowed to be added to each food category is strictly regulated. The application submitted by the petitioner, to use a new food additive, has to full fill certain extensive requirements. In order to help the applicant, the Food Additives Working Group has issued guidelines which describe what should be included in the application and these have to be strictly followed by the applicant. According to the guidelines "Presentation of an application for assessment of a food additive prior to its authorization" from 1992 (6) a lot of information should be submitted by the petitioner. This includes administrative data, technical data (specification, manufacturing process, purity, methods of analysis, etc.) and toxicological data (principles of toxicological evaluation, study protocols, toxicological section reporting data, review of results and conclusion, etc.). In the USA the FDA provides the correspondent guidance of safety evaluation in their so-called "Red book".

The requirements for the toxicological programme (Figure 1) are in many ways similar to those for drugs. However, since additives are used in foods that may be consumed by humans of all ages and sometimes during the whole life time, adverse effects are not acceptable. The situation is somewhat different for drugs, since benefits of drug use are considered in relation to risks/adverse effects. The present guidelines from 1992 are presently under re-evaluation and a new edition will be available early next year (9).

Animal studies are needed for the safety assessment (Figure 2), and exposure studies covering selected segments of the total lifetime cannot replace lifetime studies (10). The major difference in the new guidelines will be a more pronounced focus on ADME studies (AbsorptionDistribution-Metabolism-Excretion), including species comparisons of pharmacokinetics and pharmacodynamics. There will also be more emphasis on the use of a more scientifically oriented case by case approach in designing the toxicological programme, such as the inclusion of new techniques in molecular biology, new studies of neurotoxicology, immunotoxicology and genetic toxicology.

\section{Purity and specifications of a food additive}

There are high purity requirements for food additives and the safety evaluation should include an evaluation of the production procedure and a safety evaluation of any contaminants (6). Thus, the process by which the raw materials are converted to the finished product should be described. The maximum residue levels of processing chemicals and impurities should by the petitioner be specified in the technical description of the application. The justification for the additive, as well as the reaction and fate of the additive in food, should be described. In addition, when the production procedure is changed for a previously permitted additive a new application from the petitioner is always needed. In future, SCF will also have the full responsibility for evaluating the safety and applicability of chemicals intended to be used in specific production procedures of food additives. 


\section{Setting the Acceptable Daily Intake (ADI-value)}

The quality/value of the data that can be used in risk assessment varies according to the set of data obtained from epidemiology, animal experiments and short term tests. When a food additive is already on the market it is very difficult to detect adverse effects. That is the reason for the extensive requirements for safety testing before a new food additive is permitted to be used on the market.

From the results in the toxicological file submitted by the petitioner, the SCF calculates the ADI-value for each additive (Figure 1). For the safety evaluation of pesticides and contaminants an "acute reference dose" is used to detect levels where toxic effects appear after a single dose. This "acute reference dose" has been used as a bench mark for a short-term ADI (11). Such a dose and evaluation is not applicable for food additives since the safety should cover daily intake during the whole life time, i.e. the acceptable daily intake (ADI). In 1987 the WHO defined the ADI as "An estimate by JECFA of the amount of food additive, expressed on a body weight basis, that can be ingested daily over a lifetime without appreciable health risk" (7). The "safe" dietary level or daily intake for animals is known as the "no observable effect level", NOEL. The ADI is calculated from the NOEL as follow:

$$
\mathrm{ADI}(\mathrm{mg} / \mathrm{kg} \mathrm{bw} / \text { day })=\frac{\mathrm{NOEL}}{\text { Safety factor }}
$$

Man may be more sensitive than the most sensitive species tested in the toxicological studies, or certain specific individuals and subgroups may show a greater sensitivity than the general population. Uncertainty or safety factors are used to extrapolate from a group of animals to an average human and from average humans to potentially sensitive groups (12). To allow for these possibilities a large "uncertainty factor" is applied to the NOEL, normally 100 , i.e. a safety factor of 10 is applied for intra-species differences and another factor of 10 for interspecies differences. This means that the average daily intake (ADI) will not exceed one-hundredth of that which has been shown to be without observed effects in animal tests. The need for an extra safety factor depending on the nature of toxicity have been debated (13). However, this safety factor can be reduced when pharmacokinetic and/or pharmacodynamic data are available. When human data are available it is possible to accept a safety factor of 10 , whereas when animal data are less convincing a safety factor of 1000 may be applied. Thus, a flexible approach, using additional factors, is adopted in order to perform risk assessments.

\section{"Old" food additives are re-evaluated}

There is also an ongoing process of reevaluation of the use, intake and safety of food additives that have previously been approved and are already on the market. New toxicological and epidemiological data may appear or there may be suspicion that the food consumption pattern has changed and thus the intake of certain food additives has increased. This work of reevaluation is performed by scientific groups, regulatory agencies, Nordic project groups, SCF and JECFA. The documentation of all food additives on the market is presently under evaluation by the Nordic Group on Food Toxicology and Risk Assessment (NNT). The intention is to find additives that need further evaluation or additives where the documentation is deficient in important respects. These selected additives could then be re-evaluated by SCF.

However, for many of the "old" food additives, we have good historical knowledge of their safety and use, which means that there are only a limited number of food additives that may be of concern today.

\section{Are children more sensitive than adults?}

The calculated ADI is valid for both children and adults (14). Today there is a lot of discussion whether children are more sensitive than adults, but no scientific evidence has really shown this to be true. In a workshop, organized by ILSI Europe (15), focused on the applicability of the ADI to infants and children it was strongly recommended that special safety factors for children should not be used $(14,16)$. Consequently, special ADIs should not be established and the overall ADI should cover all sensitive segments of the population, irrespective of age.

Children, however, have a higher food intake than adults, on a per $\mathrm{kg}$ body weight basis, and they also have other dietary habits and food preferences compared with adults (17). In addition, it must be borne in mind that only a very limited number of food additives are allowed to be used in food specially intended for small children.

Thus, a different exposure pattern to food additives needs to be kept in mind when they are used in products preferentially consumed by children. This may also have a precautionary impact on the risk assessment of certain food additives.

\section{What happens when the additive intake exceeds the ADI?}

Different food additives will get different ADI-values and a relatively low ADI indicate that adverse effects may have occurred at lower doses in the animal studies. For most additives a numerical ADIvalue $(\mathrm{mg} / \mathrm{kg}$ bw/day) has been determined that shows how much it is possible to eat each day during the whole life without any risks of adverse effects. As previously shown, the normally used ADI is based on animal data and is calculated with a safety factor of at least 100 . However, if there are no adverse effects, it is possible to use the additive according to the principles of Good Manufacturing Practice (quantum satis), i.e. the minimum amount necessary to produce the desired effects.

Obviously ADI does not represent an absolute threshold for toxicity. If an individual or a group of individuals exceed the ADI, this simply means that there is a reduced margin or safety factor between the intake by that individual and the no effect level in animals (18). Excursions above the ADI are probably not frequent, but it has to be realised that it may be difficult to prevent extreme consumers with bizarre food habits from exceeding the ADI (19). Consequently, it is not hazardous to health when the additive intake occasionally exceeds the ADI, although individuals should not exceed the ADI for prolonged periods. The significance of a higher intake has to be assessed on an additive by additive basis and depends on the magnitude and duration of the excess intake (18). Nevertheless, excursions of food additive intake above the ADI should always trigger additional considerations and actions (20).

\section{Possible interactions between food additives}

The amounts of the different food additives that may be added to different food stuffs are strictly regulated. However, for some foodstuffs it is possible to use a number of different food additives, sometimes with similar chemical characteristics and purpose. This has raised concern that structurally related, and even unrelated, food additives toxicologically could interact and have synergistic effects, possibly due to a potential to share common sites and mechanisms of toxic actions or common pathways of elimination. However, studies have shown that many of those additives which can not be excluded from having such synergistic effects had low intakes or even are alternatives for the same application (21). Furthermore, from these results it was concluded that syn- 
Table 2. Sweetening capacity of artificial sweeteners in relation to saccharose, including ADI-values and a calculation of how much saccharose (in terms of sweetness) that has to be consumed to reach the specific ADI.

\begin{tabular}{cccc}
\hline Sweetener & $\begin{array}{c}\text { ADI-value } \\
\mathrm{mg} / \mathrm{kg} \text { bw/day }\end{array}$ & $\begin{array}{c}\text { Times sweeter than } \\
\text { saccharose }\end{array}$ & $\begin{array}{c}\text { Amount (g) of saccharose } \\
\text { equivalent to the ADI } \\
\text { (in terms of sweetness) }\end{array}$
\end{tabular}

\begin{tabular}{lccc}
\hline Acesulphame K & $0-15$ & $130-200$ & $120-180$ \\
Aspartame & $0-40$ & approx. 200 & 480 \\
Cyclamate & $\left.0-11^{*}\right)$ & $25-30$ & 20 \\
Saccharin & $0-5$ & approx. 300 & 90
\end{tabular}

*) Opinion and suggestion to reduce the ADI of cyclamate to $0-7 \mathrm{mg} / \mathrm{kg} \mathrm{bw} /$ day has during the fall of 2000 been presented by the SCF.

ergistic effects between additives are less likely to occur and does not represent a health concern.

\section{Interactions - food additives and other environmental factors}

We are constantly exposed to nutrients, food additives and environmental pollutants that may cause toxicity and/or have effects on the immune system (22). We are also constantly invaded by a variety of micro-organisms, but mostly we do not develop clinical disease. Thus, since there may be synergistic effects and since we are concomitantly exposed to micro-organisms and compounds that at specific levels of intake may induce toxicity, it is important that interdisciplinary considerations are included and used in all future risk-assessment. This is, however, not a specific issue for food additives, but should always also be kept in mind when possible interactions are considered in the process of safety evaluation of food additives.

\section{How do we apply the ADI in risk management?}

According to the previously described safety evaluation different food additives will be assigned different ADI-values. There are different risk groups for differ-

Figure 3. Risk assessment of food additives. Important information on toxicology, food consumption and concentration of the additive in food that are needed for a relevant risk evaluation.

What is the toxic dose and the ADI-value?

- Human data

- Animal data

- Alternative methods

What is the intake of the additive from food?

- Calculation/estimation of intake

food data + chemical analysis

- consumer surveys

- biological monitoring ent food additives. For example, intake of azo colours may cause an increased frequency of hypersensitivity reactions among sensitive individuals (23), whereas high intake of sweeteners among diabetics and others who consume large amounts of artificially sweetened food may pose an increased risk that ADI is exceeded (24). In general, a low ADI indicates that adverse effects have occurred at relatively low doses in animal studies. However, for the safety assessment of human use it is important to include also the biologicalculating and chemical characteristics of the food additive. The different ADI-values for four artificial sweeteners can be used to exemplify the complexity of use and safety of food additives (Table 2). The ADI for the sweeteners is almost comparable, but there is a large difference in their practical use as well as in their stability, taste and sweetening capacity (25). For example, saccharin is ten times as sweet as cyclamate. Thus, 10 times more cyclamate has to be added to get the same sweetness, which means that there is clearly a higher risk to exceed the ADI with cyclamate than with saccharin (23). In addition, the ADI for cyclamate was recently re-evaluted by the SCF and it was suggested that the ADI should be decreased to $7 \mathrm{mg} / \mathrm{kg}$ bw/day. This means that the total intake may have to be further decreased. This low sweetness combined with high estimated intake is the reason why, in order to keep cyclamate intake below the ADI, Sweden previously prohibited the use of cyclamate in products other than table top sweeteners.

\section{What levels of additives are actually used?}

Sales data from GfK (Gesellschaft für Konsumentmarkt und absatzforschung), a company that registers the total quantity of different food products sold by individual dealers, can be used to estimate the total consumption of a certain food product. Using these data, a potential high consumption can be identified and also indicate whether a specific food additive in these products may be over-consumed or if there is no evident risk that the ADI is exceeded. Using such calculations, food additives of high priority can be identified and monitored. It is also possible that this monitoring could partly be performed in co-operation with the producers, since they have to document the amount of each food additive used for each specific food product.

When it was checked with the producers in Sweden, the added amount of, for example, sweeteners in light soft drinks was mostly below the maximum permitted concentrations. For example, the added amount of aspartame is usually 270 $500 \mathrm{mg} / \mathrm{l}$ (maximum level $600 \mathrm{mg} / \mathrm{l}$ ), saccharin $12-30 \mathrm{mg} / \mathrm{l}$ (maximum level $80 \mathrm{mg} / \mathrm{l})$ and acesulfame $\mathrm{K} 50-210 \mathrm{mg} / \mathrm{l}$ (maximum level $350 \mathrm{mg} / \mathrm{l}$ ). These data are comparable to the results obtained in a Norwegian intake study on sweeteners, a project within the Nordic co-operative work (26), showing that light soft drinks had lower than maximum concentrations of the sweeteners. Thus, it can be concluded that, at least for sweeteners, the producers seem to comply with the regulations.

\section{Which food additives need to be monitored?}

There are several types of information that have to be available before a human risk assessment of food addditive intake can be performed (Figure 3). Information about the toxic dose and adverse reactions can be obtained from human and animal studies and data from alternative methods as previously described. This forms the basis for calculating the ADI and a safe intake. However, it is also important that the use of food additives is toxicologically acceptable. Depending on the level of ADI and in which foodstuffs and at what levels the additive is going to be used, it is important to calculate the total food additive intake of the individual normal consumer in order to avoid exceeding the ADI. Thus, information about the actual use of food additives and intake of food that contains the specific additive is critical. This information can be obtained from food additive content and/or food intake monitoring programmes. In addition, in the Swedish food regulations from the NFA ("Kungörelse om livsmedelstillsatser") the maximum permitted amount of each additive is specified for each group of foodstuffs (27)

With several hundred food additives on the market, many of them widely used in different kinds of food products, it is impossible to monitor the intake and use of all additives. A SCOOP (Scientific Cooperation between the European Union 
and Norway) project called "Development of methodologies for the monitoring of food additive intake across the European Union" was completed recently (28). In the project report a restricted strategy for monitoring food additive use and intake was presented. It is only possible to perform and focus monitoring on a randomised selection of food additives and products. Depending on the size of ADI and in which foodstuff the additive is going to be used, it is important in risk assessment to calculate the normal consumer intake in order to prevent the consumers from exceeding the ADI.

The most important food additives to monitor have to be identified and available resources focused on those. The SCOOP strategy concludes that many food additives may be used in unrestricted amounts (quantum satis) and many are used in small amounts and only in a few food products (28). Thus, efforts should be focused on those food additives that are used in many different food products, in food products that are consumed in high amounts, or when there is an evident risk that some groups or individuals may exceed the ADI. Here we have certain risk groups, such as children, diabetics, ethnic groups, etc. By using the SCOOP strategy resources could be focused on additives that may cause concern. Thus, only a few dozen of the several hundred food additives on the market may need a complete monitoring. There are several different ways to identify and estimate the intake of additives, but this is difficult, expensive and time consuming and could be performed in several different ways (28-31).

\section{Methodology of food additive intake}

Which method that is the most suitable depends on the available information and the type of estimates that are required. Since intake is not constant for each individual or between individuals in a population, the distribution of intakes across the population is likely to be different if it is measured over a short period compared with the same measurement made over a longer time period. Furthermore, the consumption is often more concentrated to certain individuals rather than spread generally over the total population. The capacity of food consumption surveys can be enhanced by combination with a qualitative food frequency questionnaire (32). When the distribution of individual food intakes is available the estimation of extreme levels of intake is possible, but with precautions (33). When using techniques of worst case analysis there is an evident risk that the ADI is exceeded (34). Possible study methods that can be used for estimation of the intake of food additives are the following:

Per capita estimates: It requires an estimate of the total amount of the food additive entering the food supply in a given country or a region. This amount divided by the number of consumers gives a figure for the average intake. It is a simple calculation, but it gives no information on the distribution of intake within the population. The method is used for monitoring trends in additive usage. For example, it is possible to determine whether the use of an additive is increasing or decreasing by repeating the usage survey at regular intervals.

By using sales data from GfK (Gesellschaft fur Konsumentmarkt und absatzforschung) it is possible to estimate the total consumption of a certain food product. With these data available, a potential high consumption can be identified and also indicate whether the ADI of a specific food additive is exceeded.

Duplicate diet studies: A selected group of individuals is asked to retain duplicate portions of all the food they consume over the study period. These samples are aggregated and analysed for the substance(s) of interest. This method requires a high degree of co-operation and considerable effort from the participants. Realistically this study can only be undertaken over short periods. It is especially useful for studying specific population groups assumed to have a high intake of the substance(s) of interest.

Calculations using data on food consumption and additive occurrence: The most common approach to estimate the intake of food additives is to combine the information on the occurrence of the additive and the consumption of the specific food that contains the additive. Additive occurrence can be obtained from several sources, such as maximum permitted levels, technological levels, manufactures data and analytical data. Food consumption information can be obtained from trade data (including market research), national diet studies at the level of the household, national diet studies at the individual level, whether by 24 hour recall, diary record, dietary history or food frequency questionnaires, as well as from other more limited dietary surveys concentrating on population subgroups, geographic regions and/or specific foods.

Biological marker of exposure: Saccharin is, for example, not metabolised in the body and is excreted unchanged in the urine. It is therefore possible to estimate the intake by measuring the amount present in urine over a 24 -hour period, since it will approximately be equal to the amount present in that individuals diet. The parent compound, metabolites or other biological markers of exposure can be used in these studies.

The budget method: This was originally developed in Denmark as a simple, inexpensive way of assessing proposed maximum use levels of food additives to ensure that the ADIs for the additives are not exceeded. The method is designed to cover the worst case scenario and, therefore, exaggerates potential additive intake. The method is applicable for assessing potential maximum intake in countries with different eating habits. The budget method is, however, unsuitable for predicting what consumers are actually ingesting. Where more precise information on intake is considered necessary, more precise calculations should be performed. The budget method is valid internationally as it is based on the fact that there is a physiological upper limit to the amount of food and drink, and thus of food additives, that can be consumed each day. A further assumption is that only a certain proportion of the diet is likely to contain food additives. Using appropriate estimates for the upper limits of food and drink, which can be consumed each day, the budget method allows regulators to allocate the ADI of a food additive between food and beverages and also to set maximum levels of use.

New methods under development: Normally the methods calculate possible intakes and do not take count of the probability of the intakes actually occurring. Thus, there is a future need for new and refined methods. Stochastic modelling is a method in which there is a growing interest by agencies (personal communication J. Lambe). The US Environmental Protection Agency (EPA) has stated that probabilistic analysis techniques can be viable statistical tools for analysing variability and uncertainty in risk assessments.

\section{Alarm in the media}

Even though food additives are well regulated both regarding intake and risks there is a never ending debate in the media how dangerous food additives are. This is especially true for the artificial ones. There are several examples, but in this article we will focus mainly on the artificial sweetener aspartame (E951) and briefly on glutamate (E620-625), which both have caused a lot of debate during many years.

Glutamate: The concern regarding glutamate has developed from people visiting the Far East reporting that they have experienced a kind of hypersensitivity reaction after eating food containing glutamate. 
However, there is no scientific evidence in the literature that glutamate can cause these effects (35). Glutamic acid comprises some $20 \%$ of dietary protein and the food additive use does not markedly increase the total body burden. The explanation for the reported reaction may be the normal use of a variety of strong spices in these food cultures. Thus, based on present toxicological and epidemiological studies there is no scientific reasons that invalidate the appropriateness of allocating an ADI not specified to glutamate (36).

Aspartame: Of all the 300 food additives on todays market aspartame is the most investigated additive and it has been on the market for almost 20 years (37). Even though aspartame (composed of the three naturally constituents phenylalanine, aspartic acid and methanol) is metabolised in the body as other proteins and generates a small amount of energy $(17 \mathrm{~kJ} / \mathrm{g})$ it is regarded as non-caloric (38-40). In the media it has repeatedly been stated that aspartame may cause an array of adverse reactions, such as headache, difficulties to remember, neurological problems, excema, heart problems, weight changes, hallucinations, difficulties to breath, hyperactivity, mental retardness in children, and brain tumours. Nothing of this is true (41). These rumours developed as a result of a clinical intake study of aspartame performed by the Center for Disease Control (CDC) in USA (37). In this study CDC asked questions to find clinical effects, but no adverse reactions were reported. Today these questions have been turned into actual findings of adverse reactions. Nevertheless, after this study that showed aspartame to be safe, the use as a sweetener was by FDA in 1983 extended to all food stuffs.

The reason why people still are concerned about aspartame is partly due to an article by Olney et al. (42) in which the authors have misused data on CNS (brain) tumour incidence during 75-92 from SEER (41), the cancer register in USA. Olney is right in that there was a small increase in tumour incidence around the time for introduction of aspartame, but it is scientifically really doubtful whether an increased cancer incidence would appear at the same time as a substance is introduced on the market. Nevertheless, during the following years this increase in brain tumours flattened out even though there was a tremendous increase in aspartame consumption. Finally, during the last years there has been a decrease in brain tumours that was not even reported by Olney et al (42). After this report several countries in Europe, as well as the scientific expert organisations SCF and FDA have independently re-evaluated previous and new data. After all this new work there is still no indication of any adverse effect associated with aspartame consumption.

Recently, some publications have indicated that the eating behaviour is changed by aspartame $(43,44)$. It has even been speculated by Erlanson-Albertsson that aspartame specifically increases the hunger and appetite $(45,46)$. In the media this author has even extended this speculation to involve todays problem with body weight increases and fatness of people in the western world. However, this hypothesis has no scientific background and the results obtained in these studies are probably a normal response to a decreased food energy intake. Aspartame, as other non-caloric sweeteners, is intended to be used as a caloric-reducing agent and when the energy intake is reduced a normal physiological response would be to feel hunger. There are no animal studies, even with life-time exposure to high doses of aspartame, or human studies that show any tendency to weight increase. Thus, there is no scientific basis to support the hypothesis that an increased food intake or fatness would specifically be induced by the sweetener aspartame.

\section{Risk management and actions taken by NFA}

When alarm and debate appear in the media it is important for NFA to evaluate all possible scientific documentation and to contact other European agencies for information and discussion of possible risks associated with the consumption of the specific additive. It is fundamental to realise that a " 0 " risk does not exist and it is impossible to avoid all risks for certain individuals (47). The decisions concerning the acceptable level of risk and the size of the population at risk are political choices.

It is important for NFA to participate in international scientific expert organisations that perform safety work regarding use and intake of food additives. This information is then in various ways communicated to the consumers and media, which is especially important today when a lot of data circulate on Internet that is not scientifically based or have been critically evaluated. For this purpose NFA uses its web site and its own journal $V$ år Föda. Before it is reasonable and possible for NFA to act, scientifically based data are needed. If such data are available, actions will always immediately be taken.

There is, for example, a lot of concern in the media and among the consumers that food additives may induce cancer. This is an adverse reaction that never would be accepted by any agency. If there are only indications in the safety evaluation of a potential risk for carcinogenic effects the food additive will never be approved for use by the SCF or reach the market. In the scientific literature it has also been concluded from both epidemiological data and risk assessment of experimental data that virtually all foodborne carcinogenic risk is attributed to naturally occurring carcinogens in the diet and not to food additives (48).

\section{Additives in the future}

There is a continuous development of new and more efficient food additives. At the same time regulatory requirements are increased. In the future a new international agency within the EU will be responsible for the safety evaluation of food additives. This mean that more resources can be focused on the safety evaluation of old and new food additives. Several new additives are in the pipe-line to be marketed within the near future. One example is a new sweetener with a sweetness 500-600 times that of saccharose, which for consumer safety means that much less will be consumed of a sweetener with a higher safety. Another important step ahead will be the risk evaluation of processing agents and increased requirements in the additive purity specifications of very low residue levels of contaminants.

\section{Conclusions}

The use of food additives is, on the basis of the ADI, strictly regulated within EU. The enforced regulation should provide assurance that the ADI will not be exceeded when foods are ingested. The overall ADI should cover all segments of the population, irrespective of age. ADI does not represent a threshold for toxicity and exceeding the ADI simply means a reduced safety factor. Thus, it is not hazardous to health when the additive intake occasionally exceeds the ADI, although individuals should not exceed the ADI for prolonged periods.

Most information indicates that food additives are used well within accepted limits. However, there is a very special group of food additives, the flavouring agents, that needs to be further evaluated for safety and regulated similarly to other food additives.

There are some food additives where consumption can be assumed to be high in relation to the ADI and those have to be identified. Of the approximately 300 food additives on the market there are only a few that needs to be more thoroughly checked. For such food additives it is important that monitoring of use and intake is performed, that potentially sensitive groups and/or individuals are identified and that intake calculations are performed to ensure that the ADI is not 
exceeded. Excursions of food additive intake above the ADI should always trigger additional considerations and actions.

All additives except for the flavouring agents should be declared on the label of the package by its function and also by the name or the specific identity E-numbers. Thus, it should be possible for the consumer to identify all food additives on the package of the foodstuff. The food additive has to be of value for the consumer or necessary for the handling and distribution of the food, as well as being toxicologically acceptable according to European Community regulatory requirements. The NFA has no special recommendations regarding the consumption of food additives, except that the ADI, as determined for each specific additive by the SCF, should not be exceeded.

\section{ACKNOWLEDGEMENTS}

The valuable comments of Professor Stuart Slorach (NFA) are greatly appreciated.

\section{REFERENCES}

1. Fennema OR: Food additives - an unending controversy. Am J Clin Nutr 1987:46:201-3.

2. Zinck O, Hallas-Möller T (eds): E-nummer bogen. Tillsaetningsstoffer i maden: Virkningar og bivirkninger. Aschehoug Dansk Forlag A/S, Denmark, 1999 pp. 1-286, (ISBN 87-1112754-6). In Danish

3. Council of Europe. Natural sources of flavourings - Report No. 1. Council of Europe Publishing, Germany, 2000 pp. 1-276, (ISBN 92-871-4324-2).

4. Ilbäck N-G, Beckman-Sundh U, Busk L: Cyanider. Ett livsfarligt gift - men små mängder behöver vi. Vår Föda 1997;4:16-20. In Swedish

5. Munro IC, Kennepohl E, Kroes R: A procedure for the safety evaluation of flavouring substances. Joint FAO/WHO expert Committee on Food Additives. Fd Chem Toxic 1999;37:207-32.

6. Commission of the European Communities. Food Sciences and Techniques. Reports of the Scientific Committee on Food: Presentation of an application for assessment of a food additive prior to its authorization. 1992 (ISBN 92-8260135-8).

7. Walker R: Toxicity testing and derivation of the ADI. Food Add Contamin 1998;15:11-6.

8. Joint FAO/WHO Expert Committee on Food Additives (JECFA): Toxicological evaluation of certain Food Additives. Published as monographs in WHO Food Additives Series 19732000.

9. Commission of the European Communities. Food Sciences and Techniques. Reports of the Scientific Committee on Food: Guidance on submissions for food additive evaluations by the Scientific Committee on Food. 2001 In press

10. Knudsen I: Temporal equivalaence between test species and humans: General toxicity issues.
Reg Toxicol Pharmacol 2000;30:42-7.

11. Herrman JL: Acute intake assessment: evolution within the Codex Committee on pesticide residues. Fodd Add Contaminants 2000;17: 551-5.

12. Renwick AG: Toxicokinetics in infants and children in relation to the ADI and TDI. Food Add Contamin 1998;15:17-35.

13. Renwick AG: The use of an additional safety or uncertainty factor for nature of toxicity in the estimation of acceptable daily intake and tolerable daily intake values. Regul Toxicol Pharmacol 1995;22:250-61.

14. Larsen JC, Pascal G: Workshop on the applicability of the ADI to infants and children. Food Add Contaminants 1998;15:1-10.

15. Corti A (ed.):Intake studies - Lessons Learnt. Proceedings 1995 ISA Annual Conference, pp. 1-156, November 27, 1995, Brussels, Belgium.

16. Lawrie CA: Different dietary patterns in relation to age and the consequences for intake of food chemicals. Food Add Contamin 1998; $15: 75-82$

17. Renwick AG, Dorne JL, Walton K: An analysis of the need for an additional uncertainty factor for infants and children. Reg Toxicol Pharmacol 2000;31:286-96.

18. Renwick AG, Walker R: An analysis of the risk of exceeding the acceptable or tolerable daily intake. Regul Toxicol Pharmacol 1993;18:463-80.

19. Larsen JC, Richold M: Report of workshop on the significance of excursions of intake above the ADI. Reg Toxicol Pharmacol 2000;30:2-12.

20. Speijers GJA: Precision of estimates of an ADI (or TDI or PTWI). Reg Toxicol Pharmacol 2000;30:87-93.

21. Groten JP, Butler W, Feron VJ, Kozianowski G, Renwick AG, Walker R: An analysis of the possibility for health implications of joint actions and interactions between food additives. Reg Toxicol Pharmacol 2000;31:77-91.

22. Ilbäck N-G: The need to include assessment of synergistic effects, bioavailability, malnutrition, etc, in risk evaluation. Nordic Seminar on Toxicological and Microbiological Risk evaluation of Food, October 7-9, 1998, Köge Denmark. pp. 19-22, 2001. In press

23. Thuvander A: Hypersensitivity to azo colouring agents. Tartrazine in food may cause rash and asthma. Läkartidn 1995:92:296-8. In Swedish

24. Ilbäck N-G., Alzin M, Jahrl S, Enghardt H, Busk L: Sweetener intake and exposure study among diabetics in Sweden. SLV-rapport 2:150, 2000 (ISSN 1104-7089). In Swedish

25. Widenfalk A, Bergsten C, Ilbäck N-G: Sötningsmedel istället för socker. Vår Föda 1998;7: 12-17. In Swedish

26. Bergsten C: Inntak av kunstige sötstoffer: Acesulfam-K, aspartam, cyklamat og sakkarin. Statens naeringsmiddeltilsyn (SNT) 1998; report 4: 1-89, (ISSN 0802-1627). In Norwegian

27. Livsmedelsverkets kungörelse om livsmedelstillsatser. SLV FS 1999:22. In Swedish

28. SCOOP Report. Development of methodologies for the monitoring of food additive intake across the European Union, Task 4.2 - Final Report. SCOOP/INT/ REPORT/2, 1998.

29. Gibney MJ, Lambde J: Estimation of food additive intake: methodology overview. Food Add Contaminants 1996;13:405-10.

30. Renwick AG: Intake of intense sweeteners. In: Low-calorie sweeteners. Present and future.
Corti A (Ed.). World Rev Nutr Diet. Basel, Karger. 1999; vol 85: pp. 178-200.

31. Bergsten C, Andersen NL, Barbieri HE, Faerden K, Hallikainen A, Ilbäck N-G, Jörgensen K, Lund-Larsen K: Guidelines for intake calculations of food additives and contaminants. Report from a Nordic Expert Group, pp. 1-82, 2000 In press

32 Lambe J, Kearney J, Leclercrq C, et al. Enhancing the capacity of food consumption surveys of short duration to estimate long term consumer-only intakes by combination with a qualitative food frequency questionnaire. Food Add Contaminants 2000; 17:177-87.

33. Chambolle M: Assessment of extreme levels of chronic food intakes. Reg Toxicol Pharmacol 2000;30:13-8.

34. Hallas-Möller T: Results of a first screeningusing the budget method. Intake-studies Lessons Learnt. Proc 1995 ISA Symposium, Ed A. Corti (Brussels: International Sweeteners Assocciation), pp. 57-77

35. Stevensson DD: Monosodium glutamate and astma. Review. J Nutr 1999;130:1067-73.

36. Walker R: The significance of excursions above the ADI. Case study: Monosodium glutamate. Reg Toxicol Pharmacol 2000;30:119-21.

37. Ilbäck N-G, Beckman-Sundh U, Busk L: Sötningsmedlet aspartam. Vad är rätt och fel i debatten? Vår Föda 1997;3:24-26. In Swedish

38. Renwick AG: Clinical pharmacology-The metabolism of intense sweeteners. Xenobiotica 1986;16:1057-71.

39. Joint FAO/WHO Expert Committee on Food Additives (JECFA): Aspartame In. Toxicological evaluation of certain Food Additives. WHO Food Additives Series 1982;16: 28-32.

40. Karim A, Burns T: Metabolism and pharmacokinetics of radiolabelled aspartame in normal subjects. In: The Clinical Evaluation of a Food Additive - Assessment of Aspartame. Tschanz C, Butchko HH, Stargel WW, Kotsonis FN (Eds.). CRC Press, New York, 1996, pp.67-86.

41. Levy PS, Hedeker D: Letter to the Editor. J Neuropathol Exp Neuorol 1996;55:1280.

42. Olney JW, Farber NB, Spitznagel E, Robins LN: Increasing brain tumor rates: Is there a link to aspartame? J Neuropathol Exp Neurol 1996;55:1115-23.

43. Lavin JH, French SJ, Read NW: The effect of sucrose- and aspartame-sweetened drinks on energy intake, hunger and food choice of female, moderately restrained eaters. Internat $J$ Obesity 1997;21:37-42.

44. Melanson KJ, Westerterp-Plantega MS, Camp field LA, Saris WHM: Blood glucose and patterns in time-blinded males, after aspartame, carbohydrate and fat consumption, in relation to sweetener perception. Br J Nutr 1999;82:437-66.

45. Erlanson-Albertsson C: Aspartam - ett sötningsmedel med oväntade effekter. Scand J Nutr/Näringsforskning 2000;44:82-3. In Swedish

46. Erlansson-Albertsson C: Aptitreglering och makronäringsämnen. Perspektiv - Tidskrift om socker och näring, published by Danisco Sugar 2000;2:5-8. In Swedish

47. Verger P, Garnier-Sagne I, Leblanc J-C: Identification of risk groups for intake of food chemicals. Reg Toxicol Pharmacol 2000;30: 103-8.

48. Scheuplin RJ: Perspectives on toxicological risk - An example: Food borne carcinogenic risk. Crit Rev, Food Sci Nutr 1992;32:105-21. D 